\title{
Absence of lumpy skin disease virus in semen of vaccinated bulls following vaccination and subsequent experimental infection
}

\author{
U.I. Osuagwuh ${ }^{a}$, V. Bagla ${ }^{b}$, E.H. Venter ${ }^{b}$, C.H. Annandale ${ }^{a}$ and P.C. Irons ${ }^{a}$ \\ ${ }^{\mathrm{a}}$ Section of Reproduction, Department of Production Animal Studies, Faculty of \\ Veterinary Science, University of Pretoria, Onderstepoort 0110, South Africa \\ ${ }^{b}$ Department of Veterinary Tropical Disease, Faculty of Veterinary Science, University \\ of Pretoria, Onderstepoort 0110, South Africa
}

\begin{abstract}
Twelve serologically negative bulls were used, six were vaccinated with a modified live LSD vaccine and six unvaccinated. All were then experimentally infected with a virulent field strain of LSDV. No clinical abnormality was detected following vaccination, and mild clinical signs were seen in four vaccinated bulls following challenge. Virus was not found in semen of vaccinated bulls. Two of the unvaccinated bulls developed severe LSD and four showed mild symptoms, all excreted the virus in the semen following challenge. This study confirmed the ability of LSD vaccination to prevent the excretion of LSDV in semen of vaccinated bulls.
\end{abstract}

\section{Article Outline}

1. Introduction

2. Materials and methods

2.1. Animals and housing

2.2. Vaccine and vaccination procedure

2.3. Challenge virus and procedure

2.4. Clinical observation 
2.5. Blood sampling and semen collection

2.6. Serum neutralization test

2.7. Virus isolation

2.8. PCR

3. Results

3.1. Clinical signs

3.1.1. Unvaccinated bulls

3.1.2. Vaccinated bulls

3.2. Serum neutralization test

3.2.1. Vaccinated bulls

3.3. Viraemia

3.3.1. Unvaccinated bulls

3.3.2. Vaccinated bulls

3.4. Virus in semen

3.4.1. Unvaccinated bulls

3.4.2. Vaccinated bulls

4. Discussion

References

\section{Introduction}

The widespread use of artificial insemination in cattle production has facilitated the exchange of genetic material at the national and international level and assisted with the control of sexually transmitted diseases.

Lumpy skin disease (LSD) is caused by a virus in the genus Capripoxvirus of the family Poxviridae. It is an acute, subacute or inapparent disease in cattle and affects all ages and breeds [8] and [15]. The disease is characterized by pyrexia, generalized skin and internal pox lesions which can be seen as firm eruptions of circumscribed nodules in the skin, and generalised lymphadenopathy [8], [15] and [19]. The disease causes significant economic loss due to hide damage, loss of milk production, mastitis, infertility and death [26]. The morbidity rate in natural occurrence varies from 3 to $85 \%$. About $40-50 \%$ of 
experimentally infected animals exhibit the clinical signs, and mortality is usually less that $3 \%[2]$.

Lumpy skin disease is primarily transmitted by biting insects, particularly blood feeding insects, such as the mosquito [5]. Contact transmission between animals may occur at low rate but cannot be considered to play a significant role in transmission during epizootics [2] and [5]. Lumpy skin disease virus is excreted in the semen of susceptible bulls following experimental infection [14] and [26]. This is a potential risk in the movement of semen from countries where LSD occurs to countries free of the disease, although there is no evidence to suggest transmission via infected semen.

The disease was considered a "List A" disease by the Office International des Epizooties (OIE) due to its potential for rapid spread and ability to cause severe economic losses [18]. It is a constraint in international trade of live animals and their products.

The most widely used and viable means of controlling the disease in endemic countries is by vaccination [12]. The Neethling strain of LSDV, which is a live strain of

Capripoxvirus, has been used successfully in a vaccine for the control of LSD in southern Africa [12] and [26]. This vaccine is developed by attenuation of a field isolate in tissue culture and on the chorioallantoic membranes of embryonated hens's egg [26]. According to the manufacturers, immunity to LSD starts developing 10 days after vaccination and reaches its peak after 21 days. However, the vaccine does not necessarily confer absolute immunity to all animals vaccinated [12].

Although immunity to LSD is mainly cell-mediated, the production of antibodies is a useful indicator of the response to vaccination [12], [16] and [26]. However, literature has shown the absence of detectable levels of antibodies after vaccination in some animals which were nevertheless immune to LSD when challenged [26]. The possibility of the vaccine virus being excreted in the semen following vaccination cannot be ruled out due to the fact that the vaccine virus replicates in the body of the animal. Shedding of vaccine virus in semen has been reported using a live attenuated PRRS-vaccine in boars [23].

The first objective of this study was to determine whether LSD vaccine virus is excreted in semen following vaccination with the modified live vaccine. The second objective was to determine the efficacy of vaccination in preventing LSDV excretion in semen of 
experimentally infected vaccinated bulls. Furthermore, the study aims at incorporating vaccination into biosecurity protocols for the export of bull semen from infected countries.

\section{Materials and methods}

\subsection{Animals and housing}

Twelve unvaccinated postpubertal Dexter bulls were acquired from herds where vaccination against lumpy skin disease is not practiced. All bulls were tested to be seronegative using the serum virus neutralizing test (SNT). They were also tested for their ability to produce semen before purchase, and again before the onset of the experiment. The bulls were housed in groups of three in isolated pens within an insect proof house with concrete floor covered with bedding. The bulls were provided with forage and water ad libitum. All bulls were between 11 and 16 months of age. Ejaculation was induced in all bulls by electrical stimulation. The experimental trial was divided into three periods, i.e. periods of acclimatization, vaccination and challenge.

\subsection{Vaccine and vaccination procedure}

Six bulls were vaccinated using the attenuated Neethling vaccine (Lumpy skin disease vaccine for Cattle, Onderstepoort Biological Products Ltd., Onderstepoort, Pretoria, Republic of South Africa) after a 2-3 week acclimatization period. The vaccine was reconstituted and a $5 \mathrm{ml}$ dose was administered subcutaneously to each bull according to the manufacturer's instructions. Three weeks after the first vaccination, none of the bulls had detectable antibody titers, causing us to consider the possibility of vaccine failure. The animals were therefore vaccinated again on day 21 with a different batch of vaccine to ensure effective vaccination.

\subsection{Challenge virus and procedure}

Twenty-seven days after the second vaccination, the six vaccinated and six unvaccinated bulls were experimentally infected. The experimental material used for inoculation was a virulent South African field isolate strain V248/93 of LSDV. The virus was prepared by 
three times passaged culture on bovine dermis cell monolayers, with an infective dose titre of $10^{5} \mathrm{TCID}_{50} / \mathrm{ml}$. All bulls were inoculated intravenously with $2 \mathrm{ml}$ of this virus suspension.

\subsection{Clinical observation}

The bulls were regularly examined throughout the trial. Clinical examination and rectal temperature was done daily during the period of acclimatization and vaccination and twice daily during the period of challenge. Clinical parameters observed and recorded were the general health of the bulls, superficial inguinal lymph nodes, left and right prescapular lymph nodes, rectal temperature, skin lesions and scrotal circumference. A febrile response was defined as a rise in rectal temperature above $39.5^{\circ} \mathrm{C}$.

\subsection{Blood sampling and semen collection}

During the vaccination period, blood samples were collected twice a week and tested using the SNT. In the challenge period, blood samples were collected every other day and tested using virus isolation (VI) and SNT.

Semen samples were collected by electro-ejaculation twice a week during the vaccination period and every second day during the challenge period. Samples were tested for LSDV using PCR.

All ejaculates were collected into newly graduated sample tubes using collection funnels. Cross-contamination between animals was avoided by using different funnels for each animal for collection of all samples. Between collections, funnels were washed thoroughly with clean water, and rinsed with hot distilled water. Semen samples were frozen at $-20^{\circ} \mathrm{C}$ until PCRs were done.

\subsection{Serum neutralization test}

The SNT was done by using a 96-well, flat-bottomed cell culture microtitre plates. The test sera were diluted to $1: 5$ in a minimum essential medium (MEM) containing $5 \%$ foetal calf serum and $0.05 \mathrm{ml}$ gentamycin (stock $50 \mathrm{mg} / \mathrm{ml}$ ) and inactivated at $56{ }^{\circ} \mathrm{C}$ for $30 \mathrm{~min}$. A series of two-fold dilutions of the inactivated test serum was prepared and $100 \mu 1$ of the 
serum was added in duplicate to each of the wells. The titre of the LSDV used was determined and $100 \mu \mathrm{l}$ of a $100 \mathrm{TCID}_{50}$ was then added to each of the wells. As cell control, $200 \mu \mathrm{l}$ of MEM was added to 12 wells. For virus control, three, 10-fold dilutions of antigen $\left(100 \mathrm{TCID}_{50}\right)$ were made and $100 \mu$ of each dilution was added to $100 \mu \mathrm{l}$ of MEM in each well. The microtitre plate was incubated at $37^{\circ} \mathrm{C}$ for $1 \mathrm{~h}$. Following incubation, $80 \mu \mathrm{l}$ of bovine dermis cells at a concentration of $480,000 \mathrm{cell} / \mathrm{s} / \mathrm{ml}$ were added to all the wells.

The microtitre plates were further incubated at $37^{\circ} \mathrm{C}$ in an incubator containing $5 \% \mathrm{CO}_{2}$. Using an inverted microscope, the monolayers were examined daily for 7 days for evidence of cytopathic effect (CPE). The cell control indicated how long the cells remained viable and for how long it was possible to read the test before cell degeneration. The absence of CPE was an indication of neutralization and therefore a positive antibody reaction.

\subsection{Virus isolation}

Bovine dermis cells at $\pm 50 \%$ confluence grown in $25 \mathrm{~cm}^{2}$ culture flasks were infected with $0.5 \mathrm{ml}$ heparinized blood. After $24 \mathrm{~h}$ the medium was removed and the cells were washed twice with buffered phosphate saline containing $\mathrm{Mg}^{2+}$ and $\mathrm{Ca}^{2+}(\mathrm{PBS}+)$ containing $0.05 \mathrm{ml}$ gentamycin (stock $50 \mathrm{mg} / \mathrm{ml}$ ). The medium was replaced with MEM

containing $5 \%$ foetal calf serum and gentamycin (stock $50 \mathrm{mg} / \mathrm{ml}$ ). The cell cultures were observed daily for CPE. After 14 days, negative cultures were frozen briefly at $-70{ }^{\circ} \mathrm{C}$ and thawed. The flasks were shaken gently to break up the cell material and to release the cell-bound virus. A second passage was done and observed for 14 days. Positive cell cultures were stored at $-70{ }^{\circ} \mathrm{C}$.

\subsection{PCR}

The extraction method used was a modification from the method described by Gubbels et al. [11] and Schwartz et al. [21]. The semen samples were tested by the PCR using primers developed from the gene for viral attachment protein (Ireland and Binepal [13]), and had a forward primer of 5'-d TTTCCTGATTTTTCTTACTAT 3' and reverse primer: 5'-d AAATTATATACGTAAATAAC 3'. The size of the amplicon was $192 \mathrm{bp.}$ 
A positive control of bovine semen spiked with LSDV was used; negative semen controls consisting of bovine semen as well as a water control were included in the PCR. Amplified products were analyzed on 1.5\% agarose gels using a 100 bp DNA ladder (Whitehead Scientific Ltd.) as a molecular marker. Amplicons were visualized using an UV transilluminator at a wavelength of $300 \mathrm{~nm}$ and positive amplicons were indicated by the presence of bands corresponding to those of the positive control sample.

\section{Results}

\subsection{Clinical signs}

\subsubsection{Unvaccinated bulls}

Two of the unvaccinated bulls developed severe LSD and four showed mild to inapparent infections. In the severely affected group fever started on days 6 and 7 post-infection (p.i.) and lasted for 12 and 16 days. Multiple skin lesions developed 5 days later and corneal opacity was observed 2-3 weeks after the appearance of skin lesions. These bulls were febrile for 9 days and became depressed and inappetant. Symptoms in the other bulls were limited to transient febrile reactions and few skin lesions which did not persist.

\subsubsection{Vaccinated bulls}

No clinical abnormalities were detected following vaccination, and clinical signs were limited to mild lymph node enlargement in four bulls following challenge of the vaccinated bulls.

\subsection{Serum neutralization test}

\subsubsection{Vaccinated bulls}

Three of the vaccinated bulls were serologically positive by day 48 post-vaccination (p.v.) and four bulls by the end of the trial. One animal was found to be serologically negative at the end of the trial having been positive at day 48 p.v. Antibody titers were low following both vaccination and challenge, with maximum titers of 1:3 and 1:6, respectively. 


\subsection{Viraemia}

\subsubsection{Unvaccinated bulls}

Virus was isolated from heparinized blood samples from both of the severely affected bulls on multiple occasions, in one, seven times during days 9-21 p.i. and in the other eight times on days 9-23 p.i., these being 2 and 1 days after the onset of the fever reaction, respectively, and a day after the appearance of skin lesions. In the mildly affected group, virus was not isolated from one bull but was isolated from the three other bulls on days 15, 17 and 19 p.i., days 11, 15 and 25 and from one other bull on day 7 only (Table 1).

Table 1.

Viraemia following experimental infection of unvaccinated bulls, as determined by virus isolation

\begin{tabular}{|c|c|c|c|c|c|c|c|c|c|c|c|c|c|}
\hline \multirow[t]{2}{*}{ Clinical signs } & \multirow[t]{2}{*}{ Bulls } & \multicolumn{12}{|c|}{ Days post-infection } \\
\hline & & 7 & 9 & 11 & 13 & 15 & 17 & 19 & 21 & 23 & 25 & 27 & 29 \\
\hline \multirow[t]{2}{*}{ Severe } & $\mathrm{D}$ & - & + & + & + & + & + & + & + & - & - & - & - \\
\hline & $\mathrm{E}$ & - & + & + & + & + & + & + & + & + & - & - & - \\
\hline \multirow[t]{4}{*}{ Mild } & A & - & - & - & - & + & + & + & - & - & - & - & - \\
\hline & $\mathrm{B}$ & - & - & - & - & - & - & - & - & - & - & - & - \\
\hline & $\mathrm{C}$ & + & - & - & - & - & - & - & - & - & - & - & - \\
\hline & $\mathrm{F}$ & - & - & + & - & + & - & - & - & - & + & - & - \\
\hline
\end{tabular}

$(-)$ : Negative for virus isolation, $(+)$ : positive for virus isolation.

\subsubsection{Vaccinated bulls}

None of the vaccinated bulls were found to be viraemic after vaccination or experimental inoculation. 


\subsection{Virus in semen}

\subsubsection{Unvaccinated bulls}

The semen of all bulls except one with an inapparent infection tested positive on one or more occasions using the PCR. The presence of virus in semen is depicted in Table 2. Viral nucleic acid was detected in the severely affected bulls from day 10 p.i. until the end of the trial on day 28 p.i. The onset of the shedding of virus in semen corresponded with the day when the peak of the febrile response.

Table 2.

Presence of LSDV in semen following experimental infection, as determined by the PCR

\begin{tabular}{|l|l|l|l|l|l|l|l|l|l|l|l|l|}
\hline Clinical signs & Bulls & \multicolumn{10}{|c|}{ Days post-infection } \\
\hline & & $\mathbf{1 0}$ & $\mathbf{1 2}$ & $\mathbf{1 4}$ & $\mathbf{1 6}$ & $\mathbf{1 8}$ & $\mathbf{2 2}$ & $\mathbf{2 4}$ & $\mathbf{2 6}$ & $\mathbf{2 7}$ & $\mathbf{2 8}$ \\
\hline Severe & D & + & + & + & + & + & + & + & + & + & + \\
\hline & E & + & + & + & + & + & + & + & + & + & + \\
\hline & A & - & - & - & - & + & - & - & - & - & - \\
\hline Mild & B & - & - & - & - & - & - & - & - & + & - \\
\hline & C & - & + & + & - & - & - & + & - & + & - \\
\hline & F & - & - & - & + & - & - & - & - & - & - \\
\hline
\end{tabular}

$(-)$ : Negative for PCR, $(+)$ : positive for PCR.

One semen sample from one of the mildly affected animals tested positive on day 27 p.i. and this bull was not found to be viraemic at any stage. The other mildly affected bull tested positive on four occasions between days 12 and 27 p.i. while two other bulls tested positive once each, on days 16 and 18 p.i. (Table 2).

\subsubsection{Vaccinated bulls}

Viral nucleic acid was not detected in the semen samples of the vaccinated bulls on any day following vaccination or experimental infection. 


\section{Discussion}

The duration of viraemia among the unvaccinated bulls varied considerably and was similar to a recent study [25] where virus was isolated within a day of the onset of fever. No vaccinated bulls were found to be viraemic after experimental infection with the same strain of LSDV used in the unvaccinated bulls. It is therefore evident that vaccination did prevent viraemia.

In this study, three of the six vaccinated bulls seroconverted by the end of the vaccination period and four bulls by the end of the trial, with a rise in antibody titre in four bulls. The very low level of antibody formation found in this study is characteristic of the response of LSDV [3] and [16]. The data suggest that high antibody titres were not necessary to prevent or reduce the manifestation or severity of the clinical signs of the disease in the bulls when experimentally infected. This is thought to be due to the fact that immunity to LSD infection is predominantly cell mediated [3] and [17]. Tuppurainen et al. [25] also demonstrated that the level of antibody titre is proportional with the severity of clinical disease observed in experimentally infected bulls.

In this study, the failure of any of the six bulls to seroconvert by day 21 p.v. was unexpected as the manufacturer's report indicated that immunity starts developing about 10 days after vaccination and should be fully developed after 3 weeks [12]. This prompted us to consider the possibility of vaccine failure in this instance, a phenomenon which is well documented [12] and [20]. For this reason, we decided to repeat the vaccination using a different batch of vaccine in an attempt to ensure effective protection, a deviation from our original study design. Whether different results would have been obtained had the vaccination not been repeated cannot be determined.

Previous work by this group indicated that testing for the presence of LSDV in bull semen by PCR is much more sensitive than virus isolation, due largely to the toxicity of bovine semen to tissue cultures [14] and [25]. While centrifugation and serial dilution of samples reduce the toxicity and do allow for observation of cytopathic effects [1], the sensitivity of the test is reduced by these methods. Due to the improbability of identifying additional infected samples using virus isolation and the labour and cost implications of doing virus isolation on large numbers of samples it was decided to use PCR in this study. While it is not possible to infer the presence of infective LSDV in semen from 
these results, no superior diagnostic method is currently available to achieve this goal. The bioassay used by Givens et al. to demonstrate the presence of infective bovine virus diarrhea virus in semen utilising live susceptible calves [10] was not feasible for this study due to the difficulty in sourcing known susceptible animals and the cost implications of sourcing and housing calves.

In this study, all six experimentally unvaccinated bulls excreted the virus in their semen at one point during the course of the trial. This is in agreement with the observation of Irons et al. [14]. No viral nucleic acid was detected by PCR in the vaccinated group at any point till the trial was terminated. Since the pathogenesis of seminal shedding of LSDV is not known, it is not known how vaccination prevents shedding. The skin nodules which are characteristic of LSD contain a very high concentration of the virus [6]. As nodules often develop within the genital tract in severely affected animals it is possible that LSDV is released from nodules within the genital tract into the semen during passage through the testes or epididymal ducts. However, the fact that there was transient shedding even in bulls that did not develop any clinical signs following challenge suggests that there are other mechanisms of voiding of virus in semen. Shedding of vaccine virus in semen has been shown to occur in boars vaccinated against PRRS [23] but not in boars vaccinated against Pseudorabies [4]. Vaccination was found to reduce seminal shedding of PRRS virus in boars [22] and [23] and EAV in stallions after challenge [9] and [24].

A possible explanation for the presence or absence of virus in the semen samples could arise from semen being contaminated with preputial secretions at the time of collection, or cross-contamination between samples from different bulls in subsequent collections. The semen collection technique in the present study was aimed at minimizing contamination of semen samples by trimming the preputial hairs and cleaning with clean water prior to collection. Also, different funnels were used for each animal, and between collections, these funnels were washed thoroughly with clean water and later rinsed with hot distilled water and kept in a rack to dry. Contamination of semen samples with blood during sampling has been implicated in the presence of BLV in semen [7]. No semen samples in the present study apart from samples from two unvaccinated bulls on days 13, 
17 and 19 p.i. were visibly contaminated with blood, but the presence of small amounts of blood in other samples cannot be ruled out.

Comparison with results obtained from the experimentally infected vaccinated bulls and those from the non-vaccinated bulls showed that vaccination prevented the excretion of LSDV in the semen of experimentally infected vaccinated bulls. Transient shedding of virus in semen of the vaccinated bulls from days out of the peak periods chosen cannot be excluded but is deemed highly unlikely. Should vaccinated animals experience severe clinical signs following infection as may likely occur [12], the possibility of seminal shedding cannot be ruled out.

The results of this study provide preliminary data on the abilities of the Neethling strain vaccine to prevent seminal shedding of LSDV when challenged. This study supports the inclusion of LSD vaccination with this vaccine as a biosecurity measure when semen is moved from LSD infected areas. It also illustrates further, based on these findings that double vaccination of clinically normal bulls against LSD would prevent the possible presence of LSDV in semen collected for export to LSD-free countries during the period immediately following the vaccination. Bulls should nevertheless be monitored for clinical signs of LSD while semen is being collected for export as an additional safeguard.

This study provides the first evidence of the absence of LSDV in bull semen following vaccination. It also illustrates the ability of LSD vaccination to prevent the excretion of LSD viral particles in semen when vaccinated bulls are experimentally infected.

\section{References}

[1] V.P. Bagla, U.I. Osuagwuh, C.H. Annandale, P.C. Irons and E.H. Venter, Elimination of toxicity and enhanced detection of lumpy skin disease virus on cell culture from experimentally infected semen samples, Onderstepoort J Vet Res 73 (2006), pp. 263-268. [2] B.J. Barnard, E. Munz, K. Dumbell and L. Prozesky, Lumpy skin disease. In: J.A.W. Coetzer, G.R. Thomson and R.C. Tustin, Editors, Infectious diseases of livestock with special reference to Southern Africa vol. 1, Oxford University Press, Cape Town (1994), pp. 604-612.

[3] V.M. Carn, Control of capripox virus infections, Vaccine 11 (1993), pp. 1275-1579. 
[4] J.M. Castro, M. Del Pozo, J. Gil, M.A. Imaz, I. Simarro and S.M. Rillo, Effect of a bioengineered pseudorabies (Aujesky's disease) vaccine on the semen quality of boars, Theriogenology 38 (1992), pp. 165-173.

[5] C.M. Chihota, L.F. Rennie, R.P. Kitching and P.S. Mellor, Mechanical transmission of lumpy skin disease virus by Aedes aegypti (Diptera: Culicidae), Epidemiol Infect 126 (2001), pp. 317-321.

[6] C.M. Chihota, L.F. Rennie, R.P. Kitching and P.S. Mellor, Attempted mechanical transmission of lumpy skin disease virus by biting insects, Med Vet Entomol 17 (2003), pp. 294-301.

[7] K.Y. Chio, D. Monke and J.L. Stott, Absence of bovine leucosis virus in semen of seropositive bulls, J Vet Diagn Invest 14 (2002), pp. 403-406.

[8] F.G. Davies, Lumpy skin disease of cattle: a growing problem in Africa and the near east, World Anim Rev 68 (1991), pp. 37-42.

[9] Y. Fukunaga, R. Wada and T. Matsumura, An attempt to protect against persistent infection of equine arteritis in the reproductive tract of stallions using formalin inactivated virus vaccine. Equine infectious disease VI, R \& W Publications Limited, Newmarket (1991) p. 239-244.

[10] M.D. Givens, A.M. Heath, K.V. Brock, B.W. Brodersen, R.L. Carson and D.A. Stringfellow, Detection of bovine viral diarrhea virus in semen obtained after inoculation of seronegative postpubertal bulls, Am J Vet Res 64 (2003), pp. 428-434.

[11] M.J. Gubbels, A.P. De Vos, M. Van der Weide, J. Viseras, L.M. Schouls and E. De Vries et al., Simultaneous detection of bovine Theileria and Babesia species by reverse line blot hybridization, J Clin Microbiol 37 (1999), pp. 782-789.

[12] P. Hunter and D. Wallace, Lumpy skin disease in southern Africa. A review of the disease and aspects of control, J S Afr Vet Assoc 72 (2001), pp. 68-71.

[13] D.C. Ireland and Y.S. Binepal, Improved detection of capripox virus in biopsy samples by polymerase chain reaction, J Virol Methods 74 (1998), pp. 1-7.

[14] P.C. Irons, E.S.M. Tuppurainen and E.H. Venter, Excretion of lumpy skin disease virus in bull semen, Theriogenology 63 (2005), pp. 1290-1297.

[15] R.P. Kitching and W.P. Taylor, Transmission of capripoxviruses, Res Vet Sci 39 (1985), pp. 196-199. 
[16] R.P. Kitching and J.M. Hammond, Poxvirus, infection and immunity (3rd ed.). In: I.M. Roitt and P.J. Delves, Editors, Encyclopaedia of immunology vol. 3 (1992), pp. 1261-1264.

[17] Kitching RP, Carn V. Lumpy skin disease: in manual of diagnostic tests and vaccines for terrestrial animals; 2004.

[18] OIE Manual Bulletin Office International des Epizooties, Paris, France: World Organization for Animal Health 1996.

[19] L. Prozesky and B.J.H. Barnard, A study of the pathology of lumpy skin disease in cattle, Onderstepoort J Vet Res 49 (1982), pp. 167-175.

[20] J.A. Roth, Mechanistic bases for adverse vaccine reaction and vaccine failure, Vet Vacc Diagn 41 (1999), pp. 682-696.

[21] I. Schwartz, S. Varde, R.B. Nadelman, G.P. Wormser and D. Fish, Inhibition of efficient polymerase chain reaction amplification of Borrelia burgdorferi DNA in blood fed ticks, Am J Trop Med Hyg 56 (1997), pp. 339-342.

[22] S.L. Swenson, H.T. Hill, J.J. Zimmerman, L.E. Evans, R.W. Wills and K.J.

Schwartz et al., Preliminary assessment of an inactivated PRRS virus vaccine on the excretion of virus in semen, Swine Health Prod 3 (1995), pp. 244-247.

[23] L.N. Thomas, N. Jens, P. Have, B. Poul, R. Hoff-Jorgensen and A. Botner, Examination of virus shedding in semen from vaccinated previously infected boars after experimental challenge with porcine reproductive and respiratory syndrome virus, Vet Microbiol 54 (1997), pp. 101-112.

[24] P.J. Timoney, Equine viral artertis: How serious is the threat to British horse population?, Br Vet J 148 (1992), pp. 177-180.

[25] E.S.M. Tuppurainen, E.H. Venter and J.A.W. Coetzer, The detection of lumpy skin disease virus in samples of experimentally infected cattle using different diagnostic techniques, Onderstepoort J Vet Res 72 (2005), pp. 153-164.

[26] K.E. Weiss, Lumpy skin disease virus, Virol Monograph 3 (1968), pp. 111-131.

Corresponding author. Tel.: +27 12529 8019; fax: +27 125298314 . 